\title{
Effect of internet use for health information and internet addiction on adolescents female high school' health lifestyle
}

\author{
Amany Abdrbo *1,2, Salwa Hassanein ${ }^{2,3}$ \\ ${ }^{1}$ Nursing Administration Department, Faculty of Nursing, Cairo University, Cairo, Egypt \\ ${ }^{2}$ College of Nursing, King Saud Bin Abdulaziz University for Health Sciences, Al Ahsa, KSA \\ ${ }^{3}$ Community Nursing Department, Faculty of Nursing, Cairo University, Cairo, Egypt
}

Received: April 10, 2017

DOI: $10.5430 /$ jnep.v7n12p10
Accepted: June 28, 2017

Online Published: July 10, 2017

\begin{abstract}
Background and objective: There is not enough evidence linking attitudes toward using the Internet to gather health information and adolescents' lifestyles. The objective of this study is to assess the effect of Internet use for gathering health information and Internet addiction on adolescents' health lifestyles in Saudi Arabia.

Methods: A descriptive correlational cross-sectional design was utilized to collect data from a convenience sample of 456 high-school-aged female adolescents, who completed self-administered questionnaires consisting of demographic data, attitudes toward Internet use, Internet use for seeking health information, Internet use to communicate about health, Internet addiction, and adolescent health lifestyles.

Results: The adolescent female high school students' average age was 16.88 years (SD = 1.05); Regression analyses revealed that the main effects of students' attitudes toward the Internet, along with how using the Internet to seek health information and to communicate about health, and Internet addiction significantly $(p<.001)$ affected these female high school students' lifestyles subscales. However, some predictors had varied effects on lifestyle subscales.

Conclusions: The general consensus of the research about Internet use among young people to date shows that adolescents use the Internet to communicate about their own health problems, but they do not address all of the dimensions of healthy lifestyle. This study will help identify lifestyle risk factors among adolescent female high school students, such as malnutrition, physical inactivity, not taking full responsibility for one's health and not communicating enough about one's health.
\end{abstract}

Key Words: Internet use for health information, Adolescents in high school, Healthy lifestyle

\section{INTRODUCTION}

The Internet is rapidly becoming a significant and integral part of our daily life, especially with younger age groups, as it is easy to access and use. ${ }^{[1]}$ In fact, using the Internet to gather health information is considered predictive of a healthy lifestyle. ${ }^{[2]}$ Reports have shown that the general
American population uses the Internet to attain health information regarding diagnosis and medical consultation, a practice which may ultimately lead to the delay or even cancellation of medical appointments. ${ }^{[3,4]}$

Adolescence is a transition from childhood to adulthood and includes rapid developmental, physical, psychological, cog-

\footnotetext{
*Correspondence: Amany Abdrbo; Email: aamanyahmed@hotmail.com; Address: College of Nursing, King Saud bin Abdulaziz University for Health Sciences, Al Ahsa, KSA.
} 
nitive, and behavioral changes. ${ }^{[5]}$ Adolescence is viewed as an appropriate time to establish healthy habits and prevent future health complications. ${ }^{[6]}$ People who were born from 1995-2012 are internationally classified as generation $\mathrm{Z}$; they have grown up with highly sophisticated media and in a computer-rich environment. They spend a lot of time online and connected through social media. ${ }^{[7]}$ The use of the Internet amongst adolescents has also made a change in their pattern of health behaviors despite the fact that they do not always have autonomy in making decisions regarding their own medical care. ${ }^{[8]}$

In Saudi Arabia, adolescents make up $20 \%$ of the population. ${ }^{[5]}$ Reported health problems among them include the following: $28 \%$ have a chronic health condition; $30 \%$ are overweight/obese; and $96 \%$ have a vitamin D deficiency. ${ }^{[6]}$

Using the Internet to gather health information could promote healthy adolescent lifestyles in a variety of ways, such as educating and motivating this population with respect to preventing and managing chronic diseases, maintaining their physical and psychosocial well-being, establishing good nutrition habits, seeking social support, and communicating along the proper channels about health. ${ }^{[9-11]}$

Internet addiction has numerous effects on adolescents' lives including potential physical, social, and psychological consequences. ${ }^{[12]}$ Most of the Internet-related studies among this population have investigated the effect of Internet addiction and adolescents' psychological health, ${ }^{[13-15]}$ yet no study has explored the Internet's effect on their health lifestyle. In Saudi Arabia, Internet addiction has been shown to have effects on psychiatric comorbidities including depression, anxiety, and stress, especially on female university students. ${ }^{[16,17]}$

The aim of the current study is to assess the effect of adolescent female high school students' attitudes toward using the Internet to seek and communicate about health information and the impact of Internet addiction on their lifestyle (life appreciation, health responsibility, social support, nutrition, physical activity, and stress management).

\section{BACKGROUND}

\subsection{Attitude toward internet use}

A study was conducted among 293 adult Malaysian females who have access to the Internet by Ahadzadeh, et al. ${ }^{[18]}$ to examine the influence of perceived health risk and health consciousness on health-related Internet use. The findings revealed that perceived health risk and health consciousness have a positive influence on health-related Internet use. Perceived usefulness of the Internet and a positive attitude toward Internet use for health-related purposes only partially mediate the influence of health consciousness on health-related Internet use, while on the other hand, they fully mediate the effect of perceived health risk on health-related Internet use. Additionally, prior studies have also shown that people who use the Internet for a variety of different health purposes are typically more health-oriented than those who do not. ${ }^{[19]}$

Previous studies about Internet use were performed to examine attitudes toward using the Internet for academic purposes as opposed to seeking and communicating about health information. For instance, Abedalaziz, et al. ${ }^{[20]}$ who conducted their study on postgraduate students in Malaysia, discovered that postgraduate students showed positive attitudes toward computer and Internet usage, primarily owing to the availability and accessibility of computers and the Internet. Further, results revealed no gender-related differences among postgraduate students' attitudes toward Internet use.

The similar findings from both studies ${ }^{[21,22]}$ as well as a similar study in Saudi Arabia ${ }^{[23]}$ revealed that there is a positive attitude to the educational use of the Internet, with no difference between male and female students in their attitudes towards Internet use. Hence, sufficient research has not yet been conducted that links attitudes toward Internet use, Internet use for seeking health information, or Internet use for communicating health information, and this absence reveals the need for further enquiry. It is therefore important to assess adolescent attitudes toward using the Internet, seeking health information online, and communicating such health information via the Internet.

\subsection{Internet use for seeking health information}

No study has investigated the relationship between Internet use for seeking health information and adolescents' lifestyles. However, two studies were conducted to investigate the relationship between the general uses of the computer with adolescents' lifestyle behaviors. One study was performed in Hong Kong among 2,110 secondary school students, of which $48 \%$ were female, and the other took place in China among 9,532 high school students, and $49.5 \%$ of that sample were female. Both studies reported that males tend to use the Internet more than females. However, the purpose of the use differed by gender. Females were more likely to use the Internet for seeking information, completing school assignments, and social communication, while males used the Internet for playing games and entertainment. ${ }^{[2,24]}$

Additionally, the Hong Kong study revealed a positive correlation between Internet use and social support and socialphysical activities. In China, males engaged more in physical activities, and had longer sleeping hours than females, who, in contrast had better social relationships than males. Among 
both genders, using the Internet to find information positively affected their lifestyles. ${ }^{[2]}$

A cross-sectional study was conducted among Syrian adolescents in 2014 to study the difference between male and female Internet use hours, nutritional habits, and lifestyles. The study showed that males were more likely to consume fast foods, soft drinks, and dairy products, and they would more frequently have a "dinner" meal than females. However, females consumed more fruits and vegetables and more often skipped breakfast in comparison to males. Furthermore, males tended to participate more in physical activities and Internet use than females. ${ }^{[10]}$

\subsection{Internet use for communication about health}

A systematic review ${ }^{[25]}$ identified the use of social media for communicating about health from 98 selected studies among populations whose ages ranged from 11-34 years old. The samples included more female than male users. These studies indicated that using social media for communicating about health increased the chances for younger populations to enhance their health information, especially with regard to quitting smoking, getting emotional support, and discussing sensitive concerns with health professionals.

Regarding Internet use for both seeking and communicating about health information, studies indicate that the Internet acts as a global tool that provides various links and web pages in order to meet users' needs, such as gaining information about health and offering different communication methods. ${ }^{[26]}$ Two cross-sectional studies were conducted to discover adolescents' experience with using the Internet to seek out (or gather) health information. One study, ${ }^{[27]}$ investigated a Catholic adolescent group while Jiménez-Pernett, et al. ${ }^{[1]}$ investigated a sample of Spanish adolescents. Their results were consistent, as they found that most of the adolescents are satisfied and at ease with using the Internet to get health information about topics such as skin care, cosmetics, body image, diet habits, and exercise. In George Ettel III, et al. ${ }^{[27]}$ study, high school students reported that they communicate about their health issues with their teachers more than their physicians, and they modified their behavior/lifestyle according to information they accessed on the Internet.

\subsection{Internet addiction}

Internet use rates have increased by $40 \%$ worldwide, and in some countries this exceeds $80 \%$ as reported by statistics gathered about world Internet user and user populations, ${ }^{[28]}$ including the rapid growth of Internet users in Africa and the Middle East. ${ }^{[29]}$ Internet addiction is one of the concepts that may have an effect on the behavioral and psychological development of adolescents. ${ }^{[30]}$
Internet use among adolescent is increasing steadily, and it has been reported that one in four seek online health information. ${ }^{[31]}$ The most common reason that adolescents use the Internet as a health resource is to search for information about a personal health problem. One's experience with seeking health information via the Internet is influenced by age-specific aspects of lifestyle and health status. ${ }^{[32]}$ Current studies indicate that females in general are more likely to search for health information. ${ }^{[33]}$

Two cross-sectional studies were conducted in different geographical areas: one of them in 11 European countries, ${ }^{[34]}$ and the other in Athens, Greece. ${ }^{[35]}$ These studies assessed pathological Internet use and its influences on psychosocial factors among adolescents. Both determined that males are more likely to be pathological Internet users and use chat rooms, but using the Internet had different effects on academic performance between countries. Pathological Internet use among adolescents was significantly associated with hyperactivity problems and comprehensive psychosocial maladjustment among those adolescents.

Another cross-sectional study was applied among Egyptian adolescents in Almina High School, using the Young Internet Addiction Test to examine the prevalence of pathological Internet use and identify the characteristics of Internet addiction. ${ }^{[36]}$ The study found that pathological Internet use was more common amongst males and can lead to many consequences, such as having weak family ties, experiencing sleep disturbances, and increases in becoming susceptible to physical problems such as joint stiffness. ${ }^{[36]}$ Similarly, another study that was performed to assess problematic Internet use and its association with depression and lifestyle among Qatari adolescents found that the prevalence of Internet addiction was higher in males than females. ${ }^{[37]}$ This study found that students with Internet addiction sleep fewer hours, have lower physical activity, eat fast food more frequently, and have higher depression scores than non-addicted students. ${ }^{[37]}$

In Saudi Arabia, a study was performed in Riyadh to measure the prevalence of Internet addiction and its effect on depression among 716 secondary school students. The study showed that the prevalence of Internet addiction was almost twice as high in boys (7\%) than girls (4.2\%). Also, the study indicated that Internet addiction had a significant relationship with poor sleep and depression. ${ }^{[12]}$ Another study in Taif, Saudi Arabia, included 279 university students between 18 and 26 years of age, of which 54\% were females. Internet addiction had a positive relationship with depression, anxiety, and stress and this relationship it was higher for females than it was for males. ${ }^{[16]}$ 


\subsection{Summary}

There is not enough evidence linking attitudes toward using the Internet to gather health information and adolescents' lifestyles. There is, however, a growing number of adolescents who are using the Internet to seek out health information, but they are only looking for some aspects of a healthy lifestyle, such as skin care, cosmetics, nutrition, and exercise. The general consensus of the research about Internet use among young people to date shows that most adolescents (who have online access) use the Internet to communicate about their own health problems, but they do not address all of the dimensions of healthy lifestyle. Moreover, studies on Internet addiction have only addressed its prevalence and its effect on psychological wellbeing.

The current study aims to connect all the dimensions of a healthy lifestyle, including life appreciation, health responsibility, nutrition, social support, and physical activity with attitudes toward Internet use, Internet use for seeking health information and Internet use for communicating about health. Also, it will emphasize the potential effects of Internet addiction on adolescents' health lifestyles.

\section{METHOD}

\subsection{Study design and sampling}

A descriptive cross-sectional design was utilized to collect data from a total of 456 female students who were recruited from two governmental high schools in the city of $\mathrm{Al} \mathrm{Ahsa,}$ Kingdom of Saudi Arabia using a convenience sampling technique. Due to cultural reasons, the researchers only had access to the female schools. Data was collected for the Fall Semester 2015-2016. Self-administered questionnaires with a demographic sheet were distributed in the students' classes at a time that was convenient for them. The questionnaires also provided a detailed explanation of the study's aims and instructions for filling out the questionnaire. The study was reviewed and approved by the Nursing College Research Committee and the College of Nursing Council. Participants were informed that their participation was voluntary and anonymous and that they had the right to withdraw at any time. Returning the questionnaire signified the participants' consent to be included in the study.

\subsection{Measurements}

According to some psychologists, attitude is defined as a combination of actions, resonance, feelings, and beliefs. ${ }^{[38]} \mathrm{A}$ person's attitude toward the Internet is defined as the variety of different viewpoints, beliefs, and feelings, which could be positive or negative, that determine an individual's decision to use or avoid the Internet. ${ }^{[23]}$ The current study's instrument for assessing one's "Attitude toward Internet use"[11]

Published by Sciedu Press was adapted from $\mathrm{Wu}$ and $\mathrm{Chen}^{[39]}$ questionnaire. The instrument consisted of 4 items used to ask participants about their feelings toward the use of the Internet on a 5-point Likert-type scale ( $1=$ strongly disagree, $2=$ disagree, $3=$ neutral, $4=$ agree, and $5=$ strongly agree). Mean scores were calculated, and a higher score indicated a positive attitude. The reported reliability of Cronbach's alpha was .89 among older Chinese adults, and the instrument demonstrated validity by means of a significant positive correlation $(r=.50)$ with perceived ease of Internet use. ${ }^{[11]}$

Health-related Internet use among adolescents was frequently conceptualized as self-reported hours of Internet use in general, which might lead to either memory error in reporting the correct number of hours or social desirability impacting the actual number of hours a participant is willing to report. ${ }^{[40]}$ Health-related Internet use in the current study is defined as Internet use for seeking health information and Internet use for communicating about health.

Internet use for seeking health information is defined as using the Internet for the purpose of searching for information about health from different health websites. ${ }^{[18,41]}$ Health-related Internet use was measured using two instruments, with 11 items $^{[18]}$ which were adapted from previous studies. ${ }^{[42-44]}$ Whereas Internet use for communicating about health is defined as a method of interaction between health seekers and others via Internet communication such as email, chatting, and discussion forums. ${ }^{[18,42,45]}$ Internet use to communicate about health ${ }^{[18]}$ was measured using 5 items adapted from previous studies. ${ }^{[42,44]}$

For both Internet use for seeking health information and Internet use for communicating about health, participants were asked to indicate their frequency of using the Internet on a 5-point Likert-type scale ( $5=$ always, $4=$ often, $3=$ sometimes, $2=$ rarely, and $1=$ never). A higher score indicated a higher frequency of Internet use for looking up information about health. Factor analysis indicated that all indicators were loading greater than 0.6 (range 0.655-0.931), and reliability varied from 0.90 to $0.93 .{ }^{[18]}$

Internet addiction is defined as a condition resulting from the uncontrollable use of the Internet, which leads to impairments in the social, academic, work, and psychological aspects of the person's life. ${ }^{[46,47]}$ Internet addiction was measured using Young's Diagnostic Questionnaire, which consists of 8 items with yes/no responses and was adapted from Young ${ }^{[46]}$ Five or more 'yes' responses to the eight questions indicate addiction to Internet use. Reliability, as measured by Cronbach's alpha in a study among high school students in China, was 0.72. ${ }^{[48]}$ In Cao \& Su' study, the Internet addiction group had significantly lower scores on different 
time management subscales $(p<.05)$ than the non-addicted group.

The Adolescents' Healthy Lifestyle Questionnaire ${ }^{[49]}$ was used to explore adolescents' health lifestyle. It consists of 36 items and 6 subscales: Life appreciation (7 items), Health responsibility (8 items), Nutrition (6 items), Social support (5 items), Physical activity (6 items), and Stress management (4 items). The 36 items were rated on a 5-point Likert-type scale $(5=$ always, $4=$ usually, $3=$ sometimes, $2=$ rarely, and $1=$ never). Cronbach's alpha for the total scale was 0.82 , and for the subscales it ranged from 0.75 to 0.87 . Content validity was confirmed with a committee of experts and all final corrected item-total correlations were above 0.30. ${ }^{[49]}$

A bilingual English specialist translated all of the questionnaires into Arabic. For content validity, a panel of experts reviewed the questionnaires and tested them with some students. Reliability as measured by Cronbach's alpha in the current study for the 4 questions about attitude toward Internet use was .79 , the 11 items about using the Internet for seeking health information was .88 , and the 5 questions concerning using the Internet to communicate about health items was .77.

The different subscales for the adolescents' healthy lifestyles were found to have the following figures for reliability: Cronbach's alpha for the 7 questions on life appreciation measured .69 ; the 8 health responsibility questions measured .58; the 6 items about nutrition had a reliability measure of .65; the 5 questions about social support had a Cronbach's alpha of .74; the 6 physical activity items' reliability measured .81 , and the 4 questions about stress management were found to have a Cronbach's alpha of .63.

\subsection{Statistical analysis}

Descriptive statistics (mean scores and standard deviations for conscious variables and numbers and percentages for categorical variables) were utilized to describe participants' characteristics and the study's main variables. Regression analysis models were used to assess the effect of attitude toward Internet use, Internet use for seeking health information, Internet use to communicate about health, and Internet addiction as independent variables or "predictors" on each of the adolescent healthy lifestyle subscales (life appreciation, health responsibility, nutrition, social support, physical activity, and stress management) which are considered to be the dependent variables, or "outcomes".

\section{Results}

The female adolescents' average age was $16.88(\mathrm{SD}=1.05)$; most of them were single $(\mathrm{n}=399,87.7 \%)$; the mean rating of their health on a scale from $1-5$ was $3.46(\mathrm{SD}=1.33)$; the mean of their reported hours spent on the Internet was 8.87 hours per day $(\mathrm{SD}=6.89)$. About $45 \%$ of the sample were considered addicted to the Internet $(n=201)$. Although no actual numbers were discussed with respect to the participants' families' incomes, about half of them $(51.8 \%, \mathrm{n}=$ 236) considered their family's income to be high, whereas $46.1 \%$ (210) considered their families to be middle-income.

Regarding the use of the Internet, the students rated higher mean scores for attitude toward Internet use $(\mathrm{M}=3.36, \mathrm{SD}=$ .96) than for Internet use for seeking health information (M $=2.87, \mathrm{SD}=.90)$ and communication $(\mathrm{M}=2.27, \mathrm{SD}=.98)$.

Regarding lifestyle, students rated their lifestyles on a scale from 1 to 5. They had the highest mean scores for life appreciation, which were more than $4(\mathrm{M}=4.09, \mathrm{SD}=.59)$. The next highest mean scores were for stress management $(\mathrm{M}=$ $3.48, \mathrm{SD}=.82)$, social support $(\mathrm{M}=3.43, \mathrm{SD}=.94)$, and health responsibility $(\mathrm{M}=3.05, \mathrm{SD}=.75)$. In contrast, their mean scores were lower for nutrition $(\mathrm{M}=2.94, \mathrm{SD}=.74)$ and physical activity $(\mathrm{M}=2.49, \mathrm{SD}=.98)$.

Life appreciation was regressed on the study predictors. These predictors accounted significantly for $R^{2}=.12$, $\mathrm{F}(4,440)=15.01, p=.000$. Attitude toward Internet use $(\beta=.16, p=.003)$, Internet use for seeking health information $(\beta=.21, p=.001)$, and Internet addiction $(\beta=-.10, p=$ .03) demonstrated significant effects on life appreciation, but Internet use to communicate about health $(\beta=.01, p=.90)$ did not have a significant effect (see Figure 1).

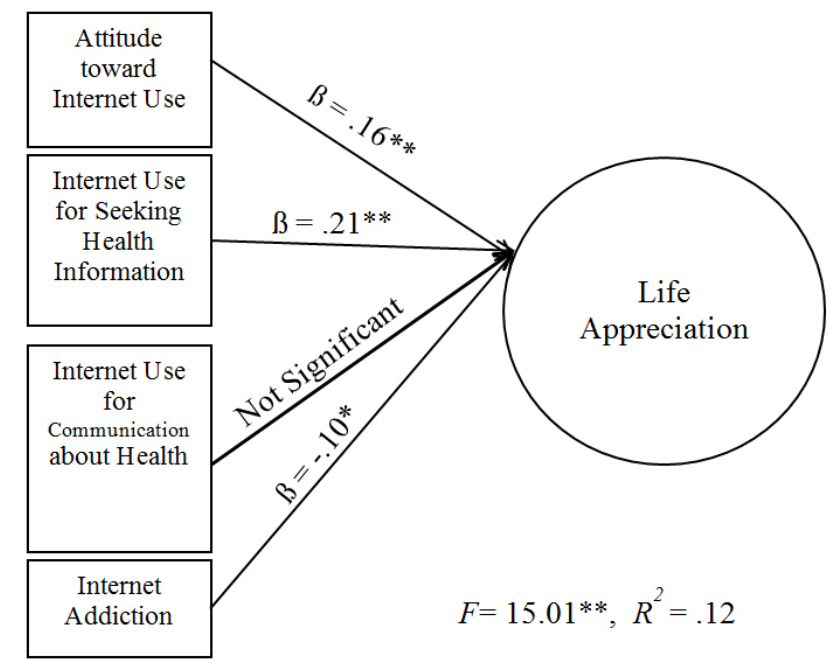

Figure 1. Regression analysis for variables explaining variance in life appreciation

Health responsibility was next regressed on the study predictors. These predictors accounted significantly for $R^{2}=.20$, $\mathrm{F}(4,440)=27.10, p=.000$. Attitude toward Internet use $(\beta=$ 
$.15, p=.005)$, Internet use for seeking health information $(\beta$ $=.19, p=.001)$, Internet use to communicate about health $(\beta$ $=.19, p=.000)$, and Internet addiction $(\beta=-.14, p=.002)$ all demonstrated significant effects on health responsibility (see Figure 2).

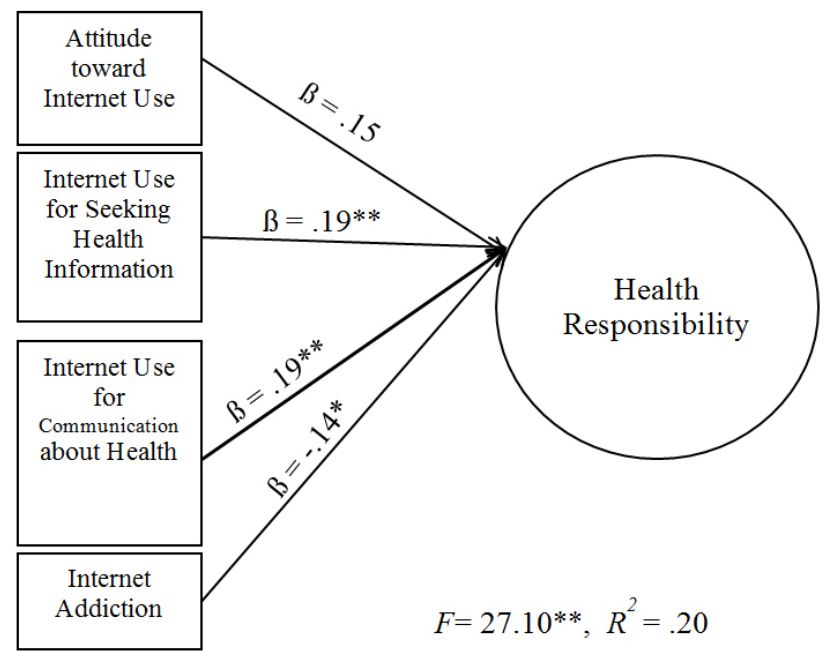

Figure 2. Regression analysis for variables explaining variance in health responsibility

For nutrition, the predictors accounted significantly for $R^{2}=$ $.13, \mathrm{~F}(4,440)=16.75, p=.000$. Attitude toward Internet use ( $\beta=.22, p=.000)$, and Internet use to communicate about health ( $\beta=.13, p=.017)$ demonstrated significant effects on nutrition, but the effects of Internet use for seeking health information $(\beta=.09, p=.135)$, and Internet addiction $(\beta=$ $-.08, p=.079$ ), were not significant (see Figure 3).

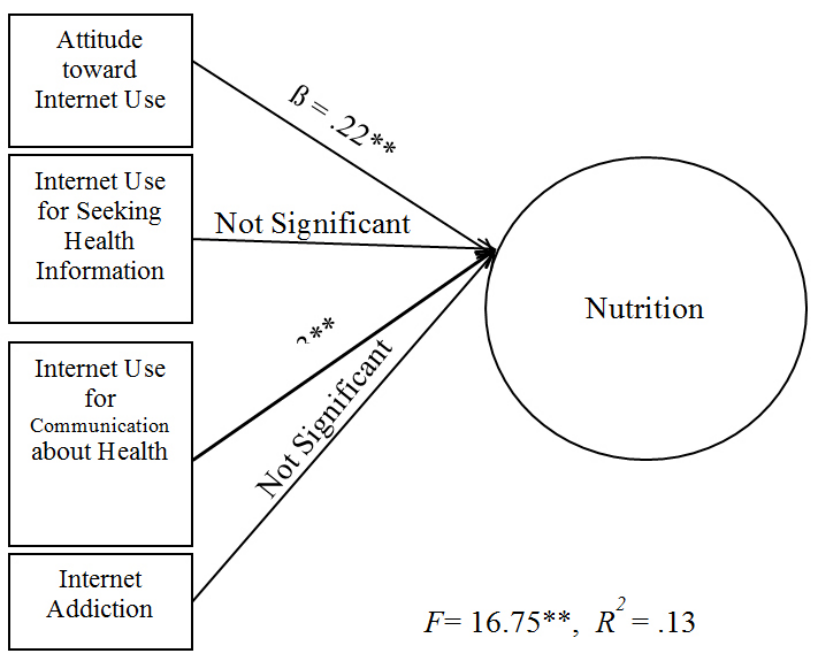

Figure 3. Regression analysis for variables explaining variance in nutriti

For social support, the predictors accounted significantly for Published by Sciedu Press
$R^{2}=.04, \mathrm{~F}(4,440)=4.63, p=.001$. Internet use to communicate about health $(\beta=.13, p=.027)$ demonstrated significant effects on social support; however, attitude toward Internet use $(\beta=.01, p=.866)$, Internet use for seeking health information $(\beta=.08, p=.203)$, and Internet addiction $(\beta=.07, p$ $=.126$ ) did not show significant effects (see Figure 4 ).

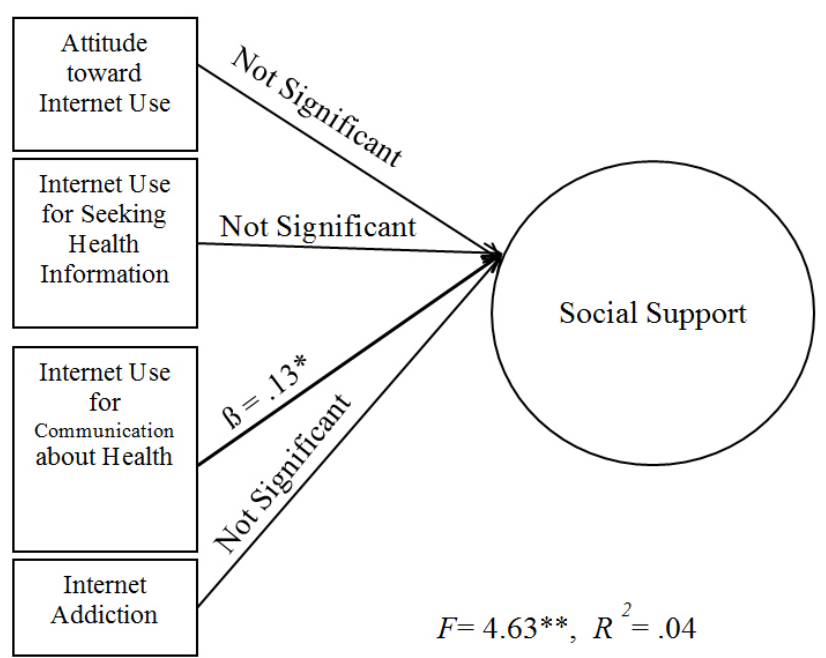

Figure 4. Regression analysis for variables explaining variance in social support

For physical activity, the predictors accounted significantly for $R^{2}=.14, \mathrm{~F}(4,440)=17.35, p=.000$. Internet use for seeking health information $(\beta=.14, p=.018)$, and Internet use to communicate about health $(\beta=.23, p=.000)$ demonstrated significant effects on physical activity, but that was not the case for attitude toward Internet use $(\beta=.07, p=$ .183 ), and Internet addiction $(\beta=.03, p=.491)$ (see Figure $5)$.

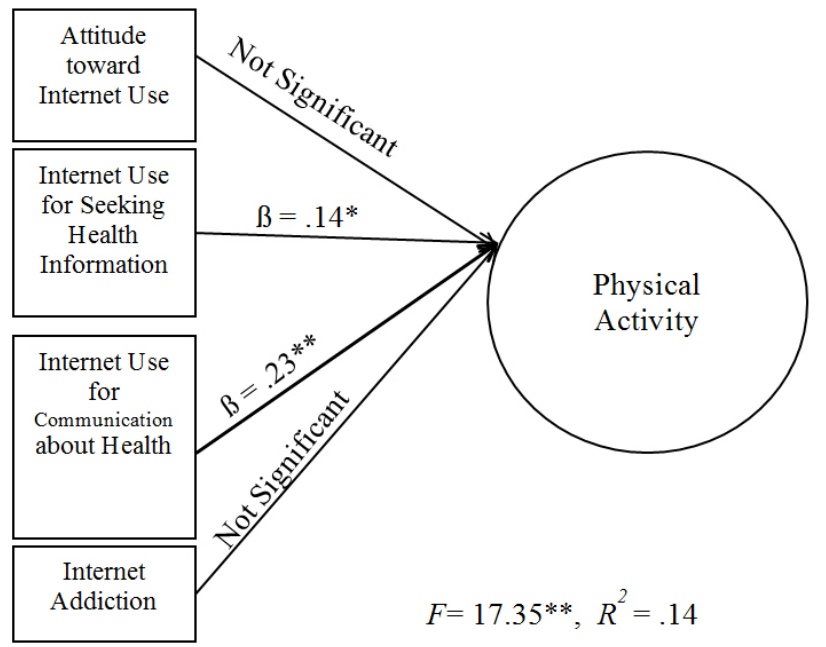

Figure 5. Regression analysis for variables explaining variance in physical activity 
For stress management, the predictors accounted significantly for $R^{2}=.16, \mathrm{~F}(4,440)=20.96, p=.000$. Attitude toward Internet use $(\beta=.18, p=.001)$, and Internet use for seeking health information $(\beta=.22, p=.000)$ demonstrated significant effects on stress management, in contrast to Internet use to communicate about health $(\beta=.08, p=.135)$ and Internet addiction $(\beta=-.04, p=.366)$ (see Figure 6).

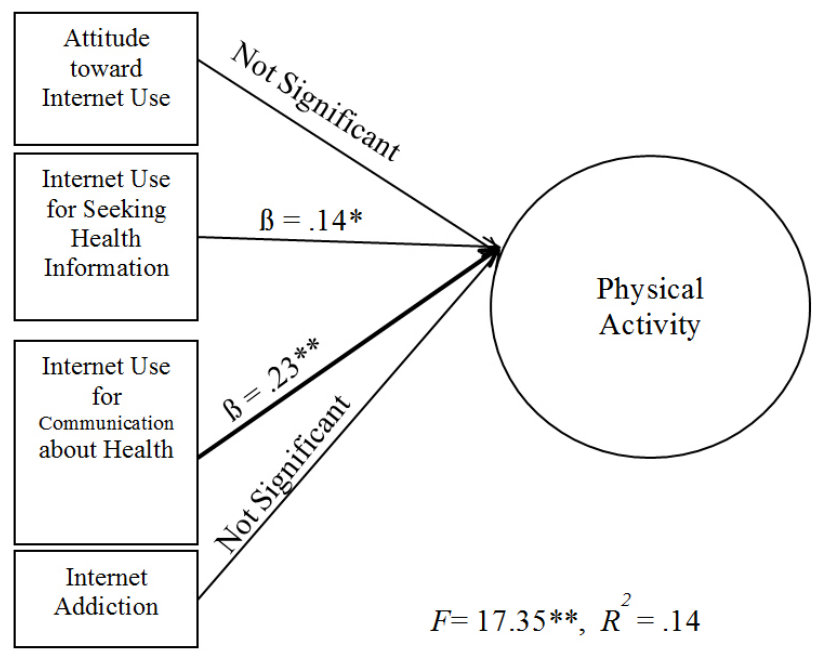

Figure 6. Regression analysis for variables explaining variance in stress management

\section{DISCUSSION}

\subsection{Attitude toward internet use for health information}

In this study, adolescent females had positive attitudes toward Internet use for health information, and a positive attitude had a significant effect on their lifestyle, specifically life appreciation, health responsibility, nutrition, and stress management. No previous study had investigated this relationship among adolescents. However, a study among adults did indicate that attitude toward Internet use for health information does have an effect on perceived health risk and a partial effect on perceived health awareness. ${ }^{[18]}$ Having a positive attitude eventually leads to changes in behavior as presumed by the theory of reasoned action, which is used to predict how an individual would be engaged in certain behaviors depending on his or her attitude. ${ }^{[50]}$

\subsection{Internet use for seeking health information}

Internet use for seeking health information has a significant effect on different dimensions of students' lifestyles, specifically life appreciation, health responsibility, physical activity, and stress management. The literature indicated that the most frequently searched topics for health care on the Internet among adolescents were diet habits, exercise, body image, cosmetics, and skin care. ${ }^{[1,27]}$ A systematic review and meta-analysis of the effects of health interventions using the Internet on health behavioral changes included 85 studies with a total of 43,236 participants from different populations. The study revealed that interventions using the Internet do have a small but significant effect on physical activity, dietary behavior, and alcohol consumption. ${ }^{[51]}$ A recent study in France among young adults (from 15-30 years old) who sought out health information online found that there is a relationship between online search frequency and changes in individuals' health behaviors. ${ }^{[8]}$

\subsection{Internet use for communicating health information}

Using the Internet to communicate about health has a significant effect on students' lifestyles, specifically in the areas of health responsibility, nutrition, social support, and physical activity. One study found that adolescents' use of the Internet for general information has a significant relationship with exercise and social relationships, ${ }^{[2]}$ and another study reported that adolescents communicate about their health issues to their teachers more than to their physicians or nurses. ${ }^{[27]}$

\subsection{Internet addiction}

About $45 \%$ of the students were considered addicted to the Internet. Internet addiction had a significant negative effect on their life appreciation and health responsibility. No study has investigated these exact relationships, but a previous study among Egyptian adolescents did investigate the characteristics of Internet addiction and found that adolescents who are addicted to the Internet had weaker family ties, more sleep disturbances, and experienced increased susceptibility to having physical problems such as joint stiffness. ${ }^{[36]}$ Similarly, another study that investigated pathological Internet use among 11,931 European adolescent high school students, of which $56.6 \%$ were female, found that there were significant associations between pathological Internet use and poor nutrition and physical inactivity. ${ }^{[30]}$

Previous studies have indicated that Internet addiction has negative effects on the users in general and in relation to their health. Therefore, it is not surprising that Internet addiction among females in this study also has negative effects, particularly on their perception of life appreciation and health responsibility. However, excessive amounts of time spent online (versus face-to-face) with friends and even family might ultimately be less rewarding or enriching for adolescents because interpersonal relationships have different dynamics online as opposed to "in real life". And, since adolescence is a time of such immense development in terms of one's sense of identity and relationships to others, it could be important to note that online social activity may not have the same (or equivalent) value for that kind of emotional and social growth. 


\subsection{Limitations}

Using a convenience sampling technique affected the generalizability of the study results to specific geographic region. Due to culture issues, the study is limited access to females only and the use of self-report and the possibility of socially desirable answers.

\subsection{Recommendations}

A number of recommendations for school health authorities and school nurses that can be drawn from the findings of this study. Increasing community awareness about healthy lifestyle behaviors, potential benefits of Internet use, and sharing health experiences could improve adolescents' attitudes and lifestyle behaviors.

Similarly, adolescents would undeniably benefit from greater awareness of and an increase in the presence of trusted health websites, and this awareness could be fostered along numerous channels: school campaigns, health informatics courses in educational curricula, accredited Arabic health websites, teaching adolescents to utilize technology to obtain accurate health information, and activating school nurse roles to coordinate health programs. These accredited websites will encourage teens to improve healthy lifestyle habits and will also offer community awareness programs to prevent important health risks among adolescents, thereby strengthening health promotion among this population. The Internet can be used to our advantage to encourage health awareness by using creative and convenient methods for health interventions that are attractive to this age group, such as encouraging videos and interactive websites or applications.

Future research should replicate the study with a larger sample size and include both male and female adolescents across different geographical areas to explore the impact of gender on the relationship between using the Internet for health information and healthy lifestyle behaviors in both rural and urban areas.

\section{Conclusion}

Adolescent female high school students had positive attitudes toward Internet use for health information but less ratings Internet use for seeking and communicating about health information. Regarding their lifestyles, they rated higher mean scores for life appreciation followed by stress management, social support, and health responsibility, whereas their mean scores were lower for physical activity and nutrition. Interestingly, all of these concepts - attitude toward Internet use for health information, using the Internet to seek health information, using the Internet to communicate about health information, and Internet addiction all had significant effects on their lifestyles. In other words, students who had highly positive attitudes about using the Internet for seeking out and communicating about health information also tended to give more positive ratings to different dimensions of their health lifestyles, such as their management of health in terms of nutrition and exercise, or how their attitude contributes to awareness about prevention and health maintenance.

\section{ACKNOWLEDGEMENTS}

Many thanks to Azhar Algafli, and Sajidah Alhumidan, former students at college of nursing, King Saud Bin Abdulaziz University for Health Sciences, who helped in data collection.

\section{CONFLICTS OF INTEREST DISCLOSURE}

There is no conflict of interest.

\section{REFERENCES}

[1] Jiménez-Pernett J, de Labry-Lima AO, Bermúdez-Tamayo C, et al. Use of the internet as a source of health information by Spanish adolescents. BMC Medical Informatics and Decision Making. 2010. PMid:20113486 https ://doi .org/10.1186/1472-6947-10-6

[2] Wang L, Luo J, Gao W, et al. The effect of Internet use on adolescents' lifestyles: A national survey. Computers in Human Behavior. 2012; 28: 2007-2013. https://doi.org/10.1016/j.chb. 2012 .04 .007

[3] Couper MP, Singer E, Levin CA, et al. Use of the Internet and ratings of information sources for medical decisions: results from the DECISIONS survey. Medical Decision Making. 2010; 30: 106S-114S, 2010. PMid:20881159 https : //doi .org/10.1177/0272989X10 377661

[4] Fox JS. The social life of health information. Washington, DC: Pew Internet \& American Life Project. 2011. Available from: http://www. pewinternet.org/2011/05/12/the-soc ial-life-of-health-inf ormation-2011/

[5] AlBuhairan FS, Olsson TM. Advancing adolescent health and health services in saudi Arabia: exploring health-care providers' training, interest, and perceptions of the health-care needs of young people. Advances in Medical Education and Practice. 2014; 5: 281 PMid:25214805 https ://doi .org/10.2147/AMEP.S66272

[6] Vitamin D Council. New study reports $96 \%$ of adolescents in Saudi Arabia are vitamin D deficient. 2015. Available from: https://www . vitamindcouncil.org/vitamin-d-news/ne w-study-reports-96-of-adolescents-in-saudi-arabi a-are-vitamin-d-deficient-09-2015/

[7] Geck C. The generation $Z$ connection: Teaching information literacy to the newest net generation. Toward a 21st-Century School Library Media Program. 2007.

[8] Beck F, Richard JB, Nguyen-Thanh V, et al. Use of the internet as a health information resource among French young adults: results 
from a nationally representative survey. Journal of Medical Internet Research. 2014. PMid:24824164 https://doi .org/10.2196/jm ir. 2934

[9] Botella C, Etchemendy E, Castilla D, et al. An e-health system for the elderly (Butler Project): a pilot study on acceptance and satisfaction. Cyberpsychol Behav. 2009. PMid:19445633 https: //doi.org/10.1089/cpb.2008.0325

[10] MusaigerA, Kalam F. Dietary habits and lifestyle among adolescents in Damascus, Syria. Annals of Agricultural and Environmental Medicine: AAEM. 2014. PMid:24959801 https://doi.org/10 $.5604 / 1232-1966.1108616$

[11] Wong C, Yeung D, Ho H, et al. Chinese older adults' Internet use for health information. Journal of Applied Gerontology: the Official Journal of the Southern Gerontological Society. 2014.

[12] Al-Hantoushi M, Al-Abdullateef S. Internet addiction among secondary school students in Riyadh city, its prevalence, correlates and relation to depression: A questionnaire survey. Int J Med Sci Public Health. 2014. https://doi.org/10.5455/ijmsph. 2013.1309 20131

[13] Desouky DES, Ibrahem RA. Internet Addiction and Psychological Morbidity among Menoufia University Students, Egypt. American Journal of Public Health Research. 2015.

[14] Li D, Zhang W, Li X, et al. Stressful life events and adolescent Internet addiction: The mediating role of psychological needs satisfaction and the moderating role of coping style. Computers in Human Behavior. 2016. https://doi.org/10.1016/j.chb. 2016.05.070

[15] Ostovar S, Allahyar N, Aminpoor H, et al. Internet Addiction and its Psychosocial Risks (Depression, Anxiety, Stress and Loneliness) among Iranian Adolescents and Young Adults: A Structural Equation Model in a Cross-Sectional Study. International Journal of Mental Health and Addiction. 2016. https://doi.org/10.1007/s114 69-015-9628-0

[16] Alshehri A, Azahrani H, Alotaibi M. Internet Addiction among Taif University Students and its Association with Psychiatric Comorbidities. IMerit Research Journal of Medicine and Medical Sciences. 2015.

[17] Khalil AI, Alharbi NB, Alhawasawi HY, et al. Prevalence of Internet Addiction among Nursing Students and the Association with their Academic Performance and Mental Health. presented at the ATINER'S Conference Paper Series, Athens. 2016.

[18] Ahadzadeh AS, Sharif SP, Ong FS, et al. Integrating Health Belief Model and Technology Acceptance Model: An Investigation of Health-Related Internet Use. Journal of medical Internet Research. 2015. PMid:25700481 https://doi.org/10.2196/jmir. 3564

[19] Dutta-Bergman MJ. Health attitudes, health cognitions, and health behaviors among Internet health information seekers: populationbased survey. J Med Internet Res. 2004. PMid:15249264 https : //doi.org/10.2196/jmir.6.2.e15

[20] Abedalaziz N, Jamaluddin S, Chin HL. Measuring attitudes toward computer and internet usage among postgraduate students in Malaysia. TOJET: The Turkish Online Journal of Educational Technology. 2013.

[21] Duggan A, Hess B, Morgan D, et al. Measuring students' attitudes toward educational use of the Internet. Journal of Educational Computing Research. 2001. https://doi.org/10.2190/GTFB-4D6 U-YCAX-UV91

[22] Hong KS, Ridzuan AA, Kuek MK. Students' attitudes toward the use of the Internet for learning: A study at a university in Malaysia. Educational Technology \& Society. 2003.

[23] Al Otaibi KN. Attitudes Towards the Use of the Internet. Psychology Research. 2012.
[24] Ho SM, Lee TM. Computer usage and its relationship with adolescent lifestyle in Hong Kong. Journal of Adolescent Health. 2001. https ://doi.org/10.1016/S1054-139X (01) 00261-0

[25] Moorhead SA, Hazlett DE, Harrison L, et al. A new dimension of health care: systematic review of the uses, benefits, and limitations of social media for health communication. J Med Internet Res. 2013. PMid:23615206 https://doi.org/10.2196/jmir.1933

[26] Hunjra AI, Rehman KU, Safwan N, et al. Students' attitude towards the uses of internet," International Journal of Business and Management. 2010.

[27] George Ettel IN, Ettel D, Wilson C, et al. How do adolescents access health information? And do they ask their physicians? The Permanente Journal. 2012. PMid:22529757

[28] Missaoui SG, Brahim T, Bouriga W, et al. Prevalence and Consequences of Internet Addiction in a Cohort of Tunisian Adolescents: A Pilot Study. Journal of Child and Adolescent Behavior. 2015.

[29] Ayatollahi J, Ayatollahi F, Bahrololoomi R. Using the internet among dental students in Yazd. Dental Research Journal. 2010.

[30] Durkee T, Carli V, Floderus B, et al. Pathological Internet Use and Risk-Behaviors among European Adolescents. International Journal of Environmental Research and Public Health. 2016. PMid:27005644 https://doi.org/10.3390/ijerph13030294

[31] Yan YY. Online health information seeking behavior in Hong Kong: an exploratory study. Journal of Medical Systems. 2010. PMid:20433053 https://doi.org/10.1007/s10916-008-922 6-9

[32] Ybarra M, Suman M. Reasons, assessments and actions taken: sex and age differences in uses of Internet health information. Health Education Research. 2008. PMid:16880222 https://doi.org/10 $.1093 /$ her/cyl062

[33] Atkinson N, Saperstein S, Pleis J. Using the internet for healthrelated activities: findings from a national probability sample. Journal of Medical Internet Research. 2009. PMid:19275980 https: //doi.org/10.2196/jmir.1035

[34] Durkee T, Kaess M, Carli V, et al. Prevalence of pathological internet use among adolescents in Europe: demographic and social factors. Addiction. 2012. PMid:22621402 https://doi .org/10.1111/j . 1360-0443.2012.03946.x

[35] Kormas G, Critselis E, Janikian M, et al. Risk factors and psychosocial characteristics of potential problematic and problematic internet use among adolescents: a cross-sectional study. BMC Public Health. 2011. PMid:21794167 https://doi .org/10.1186/1471 $-2458-11-595$

[36] Kamal NN, Mosallem FAEH. Determinants of Problematic Internet Use Among El-Minia High School Students, Egypt. International Journal of Preventive Medicine. 2013. PMid:24498499

[37] Bener A, Bhugra D. Lifestyle and depressive risk factors associated with problematic internet use in adolescents in an Arabian Gulf culture. Journal of Addiction Medicine. 2013. PMid:23666321 https://doi.org/10.1097/ADM. 0b013e3182926b1f

[38] Saeed R, Lodhi RN, Naeem A, et al. Consumer's attitude towards internet advertising in Pakistan. World Applied Sciences Journal. 2013.

[39] Wu L, Chen JL. An extension of trust and TAM model with TPB in the initial adoption of on-line tax: an empirical study. International Journal of Human-Computer Studies. 2005. https ://doi . org/10 $.1016 / j$. ijhcs.2005.03.003

[40] Valkenburg PM, Peter J. Online communication among adolescents: An integrated model of its attraction, opportunities, and risks. Journal of Adolescent Health. 2011. PMid:21257109 https : //doi.org/10.1016/j.jadohealth.2010.08.020

[41] Wilson TD. Human information behavior. Informing Science. 2000. 
[42] Hale TM, Cotten SR, Drentea P, et al. Rural-urban differences in general and health-related Internet use. American Behavioral Scientist. 2010. https://doi.org/10.1177/0002764210361685

[43] Kim J, Park HA. Development of a health information technology acceptance model using consumers' health behavior intention. Journal of Medical Internet Research. 2012.

[44] Yoo EY, Robbins LS. Understanding middle-aged women's health information seeking on the web: A theoretical approach. Journal of the American Society for Information Science and Technology. 2008. https://doi.org/10.1002/asi. 20766

[45] Valero-Aguilera B, Bermudez-Tamayo C, Garcia-Gutierrez JF, et al. Information needs and Internet use in urological and breast cancer patients. Support Care Cancer. 2014. PMid:24122406 https : //doi.org/10.1007/s00520-013-2009-y

[46] Young KS. Internet addiction: The emergence of a new clinical disorder. CyberPsychology \& Behavior. 1998. https://doi.org/10 $.1089 / \mathrm{cpb} .1998 .1 .237$
[47] Young KS, Rogers RC. The relationship between depression and Internet addiction. CyberPsychology \& Behavior. 1998. https: //doi.org/10.1089/cpb.1998.1.25

[48] Cao F, Su L. Internet addiction among Chinese adolescents: prevalence and psychological features. Child: Care, Health and Development. 2007. PMid:17439441 https://doi.org/10.1111/j.13 65-2214.2006.00715.x

[49] Taymoori P, Moeini B, Lubans D, et al. Development and psychometric testing of the Adolescent Healthy Lifestyle Questionnaire. Journal of Education and Health Promotion. 2012.

[50] Fishbein M, Ajzen I. Predicting and changing behavior: The reasoned action approach: Taylor \& Francis. 2011.

[51] Webb T, Joseph J, Yardley L, et al. Using the internet to promote health behavior change: a systematic review and meta-analysis of the impact of theoretical basis, use of behavior change techniques, and mode of delivery on efficacy. Journal of Medical Internet Research. 2010. PMid:20164043 https://doi .org/10.2196/jmir. 1376 